\title{
MOLECULAR IDENTIFICATION OF LOCAL VERTEBRATE SPECIES USING CYTOCHROME OXIDASE SUBUNIT I (COI) GENE
}

\author{
Ernieenor Faraliana Che Lah $^{1 *}$, Amartuvshin Tsolmon ${ }^{2}$, Mariana Ahamad ${ }^{1}$ \\ ${ }^{1}$ Acarology Unit, Infectious Diseases Research Centre, Institute for Medical Research, Jalan Pahang, 50588 \\ Kuala Lumpur, Malaysia \\ ${ }^{2}$ State Central Veterinary Laboratory, Zaisan, Khan-Uul District, Ulaanbaatar 210153, Mongolia \\ Corresponding author: Che Lah E.F.
}

\begin{abstract}
The aim of this study is to determine a molecular tool for identification of local vertebrate species using mtDNA COI gene. Polymerase Chain Reaction (PCR) using universal primers complementary to the conserved region of the mitochondrial DNA (mtDNA) cytochrome oxidase subunit I (COI) gene fragment, was performed on DNA of blood samples of 30 local animals in Malaysia. DNA of hosts was amplified by PCR and the products were visualized on gel electrophoresis. Twenty two sequences (73.3\%) were obtained and compared with sequences registered in GenBank and BOLD Systems databases. The BLAST results for fifteen samples (68\%) showed sequences were in congruence with morphological identification at $92 \%$ to $100 \%$ accuracy while seven sequences had no significant similarity. These results suggest that COI-based PCR is a reliable identification tool for vertebrates and can be applied for epidemiological studies on blood meal analysis of arthropod in Malaysia.
\end{abstract}

\section{Keywords}

Vertebrate, Mitochondria DNA, COI gene, Polymerase Chain Reaction.

\section{Academic Discipline And Sub-Disciplines}

Molecular biology

\section{SUBJECT CLASSIFICATION}

Genetic

\section{TYPE (METHOD/APPROACH)}

Experimental

\section{Council for Innovative Research}

Peer Review Research Publishing System

Journal: JOURNAL OF ADVANCES IN BIOTECHNOLOGY

Vol .5, No. 1

www.cirjbt.org , jbteditor@gmail.com 


\section{INTRODUCTION}

Mammals rank amongst the most studied animal groups, thus resulted in their taxonomy and species diversity well documented in literature (Wilson \& Reeder 2005). However, field identification for species of many small mammals remains difficult, in large part because of morphological variation during their development (Francis 2008, Francis et al. 2010). In vector-borne diseases, rodents are important vertebrate host animals for many zoonoses that threaten public health (Luis et al. 2013, Vazirianzadeh \& Rahdar 2013). For example, ticks (Acari: Ixodidae) play an important role in the epidemiology of disease transmission to human and animals (Gariepy et al. 2012). Ticks also rely heavily on animals especially rodents as their host to complete their life cycles (Ahantarig et al. 2008). A profound knowledge of vector host preference is important in understanding natural disease transmission cycle (Ngo \& Kramer 2003) and to minimize the risk of human infections (Christine 2011). It is important to identify natural hosts' species as fast and accurate possible for an effective outbreak management and control.

In the past, identification of the host species based on morphological taxonomic keys was commonly used for a wide variety of purposes (Kon et al. 2007, Teletchea et al. 2008). This technique is difficult because it requires animal trapping and animal maintenance in the laboratory (Wodecka et al. 2014) if further morphological or diagnosis required. Moreover, not many scientists are trained and interested in taxonomic nowadays leading to decrease number of taxonomists (Tahseen 2014). A technique is therefore needed to further provide rapid and accurate identification for use by the non-experts (Hebert et al. 2003). A standard molecular identification technique is necessary as a complement to morphological methods in order to reduce uncertainties in the identification of vertebrate. The availability of DNA sequence data of various vertebrates has opened the door for molecular based species identification approaches, such as Polymerase Chain Reaction and DNA sequencing (Alcaide et al. 2009). This alternative method of PCR-based identification is more convenient and easier to perform than the taxonomic keys (Tiwary et al. 2012, Ernieenor et al. 2013). The approach can also provide genetic references to validate field identifications made by researchers with limited taxonomic background (Borisenko et al. 2008, Lu et al. 2012).

Many molecular identification genes have been developed for species identification of hosts including mitochondrial gene regions of cytochrome b, 16S rRNA and 12S rDNA (Pun et al. 2009, Tillmar et al. 2013). Today, one standardized molecular identification approach termed DNA Barcoding has been extensively used in recent years by using cytochrome oxidase subunit I ( $\mathrm{CO}$ ) as a target gene. The features such as rapid accumulation of mutations and negligible recombination rate (Panday et al. 2014) making it particularly valuable to differentiate between species. The existence of large databases and the continued development of a comprehensive DNA barcode sequence also allow the specific identification of a bigger number of animal species (Alfonsi et al. 2013).

The objective of this study was to determine a molecular tool for identification of local vertebrate species using mtDNA COI gene. Those gene sequences were then compared with available sequences in GenBank and BOLD Systems.

\section{MATERIALS AND METHODS}

\section{Collection of Blood}

Blood was collected from a total of 30 local animals (Table 1) comprising of 18 known species of captive animals reared in National Zoo Kuala Lumpur, Laboratory Animal Research Unit in Institute for Medical Research Kuala Lumpur and wild small animals caught in Pantai Kelanang, Selangor. Two to three $\mathrm{ml}$ of blood was taken from each animal by veterinarians using appropriate humane procedure. Then it was transferred in EDTA anticoagulant tubes and sent to the Institute for Medical Research (IMR) for further analysis. The samples were kept frozen at $-20^{\circ} \mathrm{C}$ until further processed for DNA amplification.

Table 1. Name of animals used in this study

\begin{tabular}{clll}
\hline No. & \multicolumn{1}{c}{ Code } & \multicolumn{1}{c}{ Sample name (scientific name) } & \multicolumn{1}{c}{ Sample curation (source) } \\
\hline 1. & WHG (K) & White Handed Gibbon (K) (Hylobates lar) & EDTA (National Zoo) \\
2. & DD & Domestic dog (Canis lupus familiaris) & EDTA (National Zoo) \\
3. & WHG (P) & White Handed Gibbon (P) (Hylobates lar) & EDTA (National Zoo) \\
4. & PTM 1 & Pig Tailed Macaque (Macaca nemestrina) & EDTA (National Zoo) \\
5. & PTM 2 & Pig Tailed Macaque (Macaca nemestrina) & EDTA (National Zoo) \\
6. & PTM 3 & Pig Tailed Macaque (Macaca nemestrina) & EDTA (National Zoo) \\
7. & ME & Malayan Elephant (Elephas maximus) & EDTA (National Zoo) \\
8. & DL & Dusky leaf (Trachypithecus obscures) & EDTA (National Zoo) \\
9. & GP 1 & Guinea pig (Cavia porcellus) & EDTA (IMR Animal House) \\
\hline
\end{tabular}




\begin{tabular}{|c|c|c|c|}
\hline 10. & MY & Monkey (Haplorrhini sp) & EDTA (National Zoo) \\
\hline 11. & MT 5 & Malayan tiger (Panthera tigris) & EDTA (National Zoo) \\
\hline 12. & LC 1 & Leopard Cat (wild caught) (Prionailurus bengalensis) & EDTA (National Zoo) \\
\hline 13. & GP 2 & Guinea pig (Cavia porcellus) & EDTA (IMR Animal House) \\
\hline 14. & $\mathrm{SH}$ & Sheep (Ovis aries) & EDTA (National Zoo) \\
\hline 15. & RB 1 & Rabbit (male) (Lepus curpaeums) & EDTA (IMR Animal House) \\
\hline 16. & RB 2 & Rabbit (female) (Lepus curpaeums) & EDTA (IMR Animal House) \\
\hline 17. & CW 1 & Cow (Bos taurus) & EDTA (National Zoo) \\
\hline 18. & CW 2 & Cow (Bos taurus) & EDTA (National Zoo) \\
\hline 19. & GT & Goat (Capra aegagrus hircus) & EDTA (National Zoo) \\
\hline 20. & ML 1 & Monitor lizard (male) (Varanus albigularis) & EDTA (National Zoo) \\
\hline 21. & ML 2 & Monitor lizard (female) (Varanus albigularis) & EDTA (National Zoo) \\
\hline 22. & MT 4 & Malayan tiger (Panthera tigris) & EDTA (National Zoo) \\
\hline 23. & MT 3 & Malayan tiger (Panthera tigris) & EDTA (National Zoo) \\
\hline 24. & LC 2 & Lepoard cat (captive) (Prionailurus bengalensis) & EDTA (National Zoo) \\
\hline 25. & KGT 26 & Field rat (Rattus tiomanicus) & EDTA (Pantai Kelanang) \\
\hline 26. & KGT 25 & House rat (Rattus rattus) & EDTA (Pantai Kelanang) \\
\hline 27. & KGT 24 & House rat (Rattus rattus) & EDTA (Pantai Kelanang) \\
\hline 28. & KGT 23 & Squirrel (Callosciurus notatus) & EDTA (Pantai Kelanang) \\
\hline 29. & KGT 22 & Treeshrew (Tupaia glis) & EDTA (Pantai Kelanang) \\
\hline 30. & KGT 21 & House rat (Rattus rattus) & EDTA (Pantai Kelanang) \\
\hline
\end{tabular}

\section{Dilution of Blood}

Ten $\mu \mathrm{l}$ of freeze-thawed blood of each species of animals were mixed with $90 \mu \mathrm{l}$ of sterile double distilled water to produce a 1:10 dilution and used as a template in PCR amplification (Ernieenor et al. 2012).

\section{PCR Amplification of COI Gene and Gel Electrophoresis}

DNA of hosts was amplified using PCR with universal primers complementary to the conserved region of mtDNA COI gene. The primers LCOI1490 (5'-GGT CAA CAA ATC ATA AAG ATA TTG G -3') and HCO2198 (5'-TAA ACT TCA GGG TGA CCA AAA AAA TCA-3') amplified 658 bp of the COl gene (Folmer et al. 1994). The PCR was performed using KAPA Blood PCR Kit (Kapa Biosystems Inc. USA) according to the manufacturer's manual. A mixture of $25 \mu$ l solution containing $2 x$ Kappa Blood PCR mix, $0.5 \mu \mathrm{M}$ of each primer and $2.5 \mu \mathrm{l}$ of diluted blood was prepared and amplified using an Eppendorf Master Cycler Personal machine (Eppendorf, Germany) with conditions of pre-heating at $96{ }^{\circ} \mathrm{C}$ for $1 \mathrm{~min}, 35$ cycles of consecutive incubations at $94{ }^{\circ} \mathrm{C}$ for $1 \mathrm{~min}, 55^{\circ} \mathrm{C}$ for $1 \mathrm{~min}$ and $72{ }^{\circ} \mathrm{C}$ for $1.5 \mathrm{~min}$. For each PCR, a negative control containing double distilled water instead of DNA was included. Electrophoresis of amplified DNA products were conducted with $1.2 \%$ agarose gel in $0.5 x$ electrophoresis buffer and visualized under ultraviolet (UV) light after staining with $2 \mathrm{mg} / \mathrm{ml}$ ethidium bromide. A $100 \mathrm{bp}$ DNA ladder (Bioron, Germany) was used to estimate sizes of the products.

\section{DNA Purification and DNA Sequencing}

Each DNA fragment was excised from the gel using sterile, sharp gel cutter and purified using 5 Prime PCR Agarose Gel Extract Mini Kit (Hamburg, Germany) according to the manufacturer's protocol. DNA sequencing in both directions was done in the presence of the ABI PRISM ready reaction big dye terminator cycle sequencing kit (Applied Biosystems, Forster City, California, USA), following the manufacturer's instructions.

\section{Gene Sequence Analysis}

The obtained sequences were compared with available sequences in GenBank database using the Basic Local Alignment Search Tool (BLAST) program and BOLD-IDS tool from BOLD Systems. 


\section{RESULTS}

A total of 30 blood samples collected from captive, laboratory and small wild animals were amplified using PCR. A 658 bp fragment of mitochondrial $\mathrm{COI}$ gene were successfully amplified and visualized with $1.2 \%$ agarose gel electrophoresis in 22 blood samples (Figure 1). No PCR product was obtained with eight specimens despite repeated amplification and gel electrophoresis. Negative control (double distilled water) yielded no PCR product implying that only host's DNA patterns were detected in the amplifying specimens.

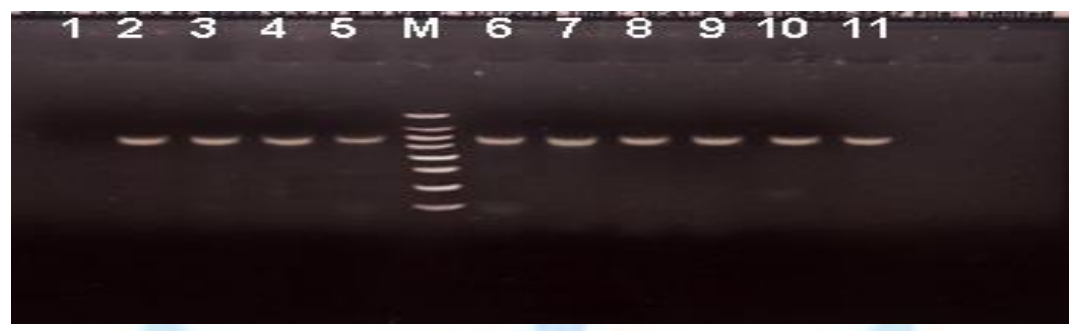

Fig 1: Gel photograph showing clear bands of $658 \mathrm{bp}$ of $\mathrm{COI}$ amplification products from local vertebrate animals. Lane 1: negative control; Lane 2: positive control; Lane 3-11: Vertebrate blood sample [GP 1, LC 1, MT5, GP 2, PTM 1, PTM 2, ME, WHG (K), WHG (P)]; Lane M: 100 bp marker.

All $22(73.3 \%)$ positive samples were sequenced and compared against GenBank and BOLD search engine. Fifteen sequences $(68 \%)$ provided correct species identification results when using GenBank BLASTn and incongruence with the morphological identification. Seven sequences give no significant similarities. The capacity of species identification through BOLD resulted only $12(54.5 \%)$ sequences generates a correct identification at species level while three sequences without identification. Sequences identification of the mtDNA COI gene through GenBank revealed that the sequence showed similarity ranging from $92-99 \%$. Twelve out of 15 sequences matched corresponding sequences of GenBank species with above 95\% similarity while three sequences (CW1, CW2, and LC2) give below 95\% similarity. In BOLD search, 12 sequences were successfully identified to species-level with a maximum identity value greater than $98 \%$. The results of blasting against corresponding sequences in databases were shown in Table 2. Eight new gene sequences which had $99 \%$ similarity were submitted for registration at GenBank/BOLD and awaiting corresponding accession numbers.

Table 2. Sequences of mitochondrial cytochrome oxidase subunit I (COI) with highest percent similarity with corresponding species in databases

\begin{tabular}{cll}
\hline Code & \multicolumn{1}{c}{ GenBank species (\% of similarity) } & \multicolumn{1}{c}{ BOLD species (\% of similarity) } \\
\hline CW 1 & Bos taurus (93) & Cavia porcellus (99.8) \\
GP 1 & Cavia porcellus (99) & - \\
LC 1 & Prionailurus bengalensis (96) & - \\
LC 2 & Prionailurus bengalensis (94) & Elephas maximus (99.8) \\
ME & Elephas maximus (99) & Panthera tigris (99.2) \\
MT 5 & Panthera tigris (99) & Macaca nemestrina (99.4) \\
PTM 1 & Macaca nemestrina (99) & Macaca nemestrina (99.4) \\
PTM 2 & Macaca nemestrina (99) & Macaca nemestrina (98.9) \\
PTM 3 & Macaca nemestrina (97) & Cavia porcellus (99.5) \\
GP 2 & Cavia porcellus (99) & Hylobates lar (99.2) \\
WHG(K) & Hylobates lar (99) & Hylobates lar (99.1) \\
WHG(P) & Hylobates lar (99) & Bos taurus (100) \\
CW 2 & Bos taurus (92) & Panthera tigris (99.4) \\
MT 3 & Panthera tigris (97) & Panthera tigris (99) \\
MT 4 & Panthera tigris (97) & Pant
\end{tabular}




\section{DISCUSSION}

This study resulted in the successful amplification of 22 vertebrate DNA from blood source. Most of the blood samples were taken from species of mammals due to many arthropod borne diseases is closely related with vertebrate mammals (DantasTorres et al. 2010, Vazirianzadeh \& Rahdar 2013). Unsuccessful amplification for eight samples namely DD, GT, ML 1, KGT 21, KGT 22, KGT 24, KGT 25 and KGT 26 could have been due to several factors. Improper storage of blood samples at -20 ${ }^{\circ} \mathrm{C}$ before sending to laboratory, not freshly isolated blood samples and insufficient lysis for some samples that may not have been grinded completely can lead to DNA degradation and causes of failure amplification (Nagata et al. 2003).

A fragment of $658 \mathrm{bp}$ of the $\mathrm{CO}$ gene was amplified for the animal species identification due to its widest taxonomic representative (Malakar et al. 2012) in nucleotide database after Cytb gene. Like other protein-coding genes, its $3^{\text {rd }}$ position nucleotide show high incidence of base substitutions, leading to a higher rate of molecular evolution (Dawnay et al. 2007) that is three times greater than ribosomal DNA. Despite the high rate of nucleotide substitution, the COI marker can discriminate between species boundaries, even among cryptic species which is congruent with morphology-based taxonomy (Cywinska et al. 2006).

Pairwise comparison of the sequences of amplified mtDNA COI gene with available sequences in databases revealed nucleotide similarities ranging from $92-100 \%$. Fifteen sequences had exact species match at the highest percent similarity and seven sequences did not have any significant similarities; those were ML 2, MY, RB 1, SH, DL, RB 2, and KGT 23 . The occurrence of not significant match probably due to the too many noise in sequencing which resulted to low complexity or short query sequence (Altschul et al. 1990, Ernieenor et al. 2013) after blasting in international databases and low concentration of purified PCR product (Agostino 2012).

Throughout the study, the identification for three sequences (LC 1, LC 2 and CW 1) that were unable to match with any records in BOLD database however gave exact match with high similarity using available sequences in GenBank. This phenomenon might be due to lack of reference sequences or no COI sequence for this local animal species (Christine 2011) but yet are available in the DNA barcoding system. Parson et al. (2000) also supported that if a species was not found in the databases, the biological significance of the matching result strongly depended on the availability of closely related species, sometimes distantly related taxon which also resulting in lower sequence similarity values.

A small (2\%) DNA sequence variation was observed between wild and captive leopard cat (LC 1 and LC 2). Both sequences provided exact match species identification corresponding to Prionailurus bengalensis with the database entry in GenBank. The small difference similarity is probably caused by single nucleotide substitutions between two sequences which can attributed to individual variation (Garamszegi et al. 2009). The COI sequence of laboratory guinea pig (GP 1 and GP 2) displayed maximum homology (99\%) with the Cavia porcellus in GenBank and BOLD database. This finding is in agreeable with facts that the abundance and adequate reference sequence of guinea pigs and other laboratory animals in the international databases could result a high homology (Altschul et al. 1990).

Samples from three Malayan tigers in this study displayed high similarity with the Panthera tigris and Panthera pardus (97\% and $92 \%$, respectively) COI mitochondrial genome in the GenBank. It may be due to the fact that genetic sequences among those two species are closely phylogenetically related to each other. A lack of differentiation between closely related species has been reported in other studies for the COI gene (Hajibabaei et al. 2007) and also the Cytb gene (Branicki et al. 2003).

The gene sequences for Pig Tailed Macaque (PTM 1 and PTM 2) samples have high similarity values (99\%) with Macaca nemestrina sequence in both databases while the PTM 3 samples showed $97-98 \%$ similarity. The nucleotide differences between samples in this study and those in databases can be attributed to individual variation, especially within species demonstrating large range of distribution (Taberlet et al. 1992). Furthermore, Avise and Walker (1999) in their study on some vertebrates concluded that less than $1 \%$ or $2 \%$ sequence divergence was typical of phylogeographical unit within a species.

A very high similarity (99\% and $99.8 \%$ ) with subject sequence in Genbank and BOLD accession was obtained for a single elephant (Elephas maximus) sample. This is not expected as there are only two different genera of elephant left in the world and only five deposited COI sequences of Elephas maximus in Genbank which contributed to small individual variation.

The COI sequence of two White Handed Gibbon samples; WHG $(\mathrm{K})$ and WHG $(\mathrm{P})$ is highly similar $(99 \%)$ to the corresponding accession Hylobates lar in GenBank. The successful molecular identification of this species is valuable since the taxonomic identification may be complicated due to sexual dichromatism and variation in coat color (Mootnick 2006). Distributions of gibbons are scarce worldwide and their numbers are declining. Evolutionary relationships of the gibbons' taxa have long been a focus of study due to their high taxonomic diversity and conservation importance (Mootnick 2006, Meyer et al. 2012). Moreover, nearly all taxa of gibbons have been classified as endangered at either the species or subspecies level (Chan et al. 2010).

This study demonstrates that $\mathrm{COI}$ gene enables accurate animal species identification where adequate reference sequence data exists. If DNA sequences for potential animals are not represented in the database, sequenced identification may be misidentified. DNA sequences analysis also relies heavily on the robustness of available sequence for the target species in the gene library. In comparison between two reference databases, it revealed that GenBank can identify more query sequences than BOLD. This can be due to the fact that GenBank presents a most comprehensive database than BOLD in term of recent 
and specific database (Ratnasingham \& Hebet 2007). These two databases also use different algorithms to calculate the similarity between query and reference sequences which can generate discrepancies in identification.

\section{CONCLUSION}

This study highlighted the expanding use of $\mathrm{CO}$ gene as a genetic marker for species identification of vertebrates especially mammals that served as ticks' host. It can be used as a tool to support morphology-based taxonomy in the absence or scarcity of experts. Addition of local vertebrate sequences in gene library is particularly important for research on arthropod-borne diseases that aims to use genetic barcodes of $\mathrm{COI}$ gene in blood meal studies. Therefore, a larger numbers and variety species of local vertebrates should be collected over the long term to obtain more sequence information for deposition in reference databases.

\section{ACKNOWLEDGEMENTS}

The authors wish to thank the Director-General of Health, Ministry of Health, Malaysia, for permission to publish this paper. Our gratitude is also dedicated to Dr Vellayan Subramaniam from Universiti Teknologi MARA (UiTM), Shah Alam who supplies the blood specimens for this project. The study was supported by SEAMEO TROPMED Regional Centre.

\section{REFERENCES}

[1] Agostino, M. 2012. Practical Bioinformatic, Chapter 3: Introduction to the BLAST Suites and BLASTN. Garland Science, $394 \mathrm{pp}$

[2] Ahantarig, A., Trinachartvanirt, W., and Wilne, J.R. 2008. Tick-borne pathogens and diseases of animals and humans in Thailand. Southeast Asian Journal of Tropical Medicine and Public Health 39(6): 1015-1032

[3] Alcaide, M., Rico, C., Ruiz, S., Soriguer, R., Munoz, J., and Figuerola, J. 2009. Disentangling vector-borne transmission networks: A universal DNA barcoding method to identify vertebrate hosts from arthropod blood meal. PLoS ONE 4(9): e7092

[4] Alfonsi, E., Meheust, E., Fuchs, S., Carpentier, F.G., Quillivic, Y., Viricel, A., Hassani, S., and Jung, J.L. 2013. The use of DNA barcoding to monitor the marine mammal biodiversity along the French Atlantic coast. Zookeys 365: 5-24

[5] Altschul, S.F., Gish, W., Miller, W., Myers, E.W., and Lipmann, D.J. 1990. Basic local alignment search tool. Journal of Molecular Biology 215: 403-410

[6] Avise, J.C., and Walker, D.E. 1999. Species realities and numbers in sexual vertebrates: perspectives from an asexually transmitted genome. Proceedings of the National Academy of Sciences USA 96: 992-995

[7] Borisenko, A.V., Lim, B.K., Ivanova, N.V., Hanner, R.H., and Hebert, P.D.N. 2008. DNA barcoding in surveys of small mammal communities: a field study in Suriname. Molecular Ecology Resources 8: 471-479

[8] Branicki, W., Kupiec, T., and Pawlowski, R. 2003. Validation of cytochrome b sequence analysis as a method of species identification. Journal of Forensic Sciences 48(1): 83-87

[9] Chan, Y.C., Roos, C., Inoue-Murayama, M., Inoue, E., Shih, C.C., Pei, K.J., and Vigilant, L. 2010. Mitochondrial genome sequences effectively reveal the phylogeny of Hylobates gibbons. PLoS ONE 5(12): e14419

[10] Christine, Z. 2011. Development of genetic barcodes for hosts of the blacklegged tick (Ixodes scapularis) in Southern New York. Dissertation, New York, United State: Fordham University

[11] Cywinska, A., Hunter, E.F., and Hebert, P.D.N. 2006. Identifying Canadian mosquito species through DNA barcodes. Medical and Veterinary Entomology 20(4): 413-424

[12] Dantas-Torres, F., Ferreira, D.R., de Melo, L.M., Lima, P.A., Sigueira, D.B., Rameh-de-Albuguergue, L.C., de Melo, A.V., and Ramos, J.A. 2010. Ticks on captive and free-living wild animals in northeastern Brazil. Experimental Applied of Acarology 50(2): 181-189

[13] Dawnay, N., Ogden, R., McEwing, R., Carvalho, G.R., and Thorpe, R.S. 2007. Validation of the barcoding gene COI for use in forensic genetic species identification. Forensic Science International 173(1): 1-6

[14] Ernieenor, F.C.L., Mariana, A., Mohd Subail, H., and Ho, T.M. 2012 Establishment of a molecular tool for blood meal identification in Malaysia. Asian Pacific Journal of Tropical Biomedicine 2(3): 223-227

[15] Ernieenor, F.C.L., Aye, T.W., Mariana, A., and Ho, T.M. 2013. PCR amplification of mitochondrial cytochrome b gene of animals in Malaysia. The Experiment 15(2): 1064-1071

[16] Folmer, O., Black, M., Hoeh, W., Lutz, R., and Vrijenhoek, R. 1994. DNA primers for amplification of mitochondrial cytochrome c oxidase subunit I from diverse metazoan invertebrates. Molecular Marine Biology and Biotechnology 3(5): 294-299 
[17] Francis, C.M. 2008. A field guide to the mammals of South-East Asia. Princeton Press, London, $392 \mathrm{pp}$

[18] Francis, C.M., Borisenko, A.V., Ivanova, N.V., Eger, J.L., Lim, B.K., Guillen-Servent, A., Kruskop, S.V., Mackie, I., and Hebert, P.D.N. 2010. The role of DNA barcodes in understanding and conservation of mammal diversity in Southeast Asia. PLoS ONE 5(9): e12575

[19] Garamszegi, L.Z., de Groot, N.G., and Bontrop, R.E. 2009. Correlated evolution of nucleotide substitution rates and allelic variation in Mhc-DRB lineages of primates. BMC Evolutionary Biology 9: 73

[20] Gariepy, T.D., Lindsay, R., Ogden, N., and Gregory, T.R. 2012. Identifying the last supper: utility of the DNA barcode library for blood meal identification in ticks. Molecular Ecology Resources 12(4): 646-652

[21] Hajibabaei, M., Singer, G.A.C., Clare, E.L., and Hebert, P.D.N. 2007. Design and applicability of DNA arrays and DNA barcodes in biodiversity monitoring. BMC Biology 5: 1-24

[22] Hebert, P.D.N., Cywinska, A., Ball, S.L., and deWaard, J.R. 2003. Biological identifications through DNA barcodes. Proceedings of the Royal Society Biological Sciences 270: 313-321

[23] Kon, T., Yoshino, T., Mukai, T., and Nishida, M. 2007. DNA sequences identify numerous cryptic of the vertebrate: A lesson from the gobioid fish Schindleria. Molecular Phylogenetics and Evolution 44(1): 53-62

[24] Lu, L., Chester, D., Zhang, W., Li, G., Ma, Y., Ma, H., Song, X., Wu, H., Meng, F., Zhu, C., and Liu, Q. 2012. Small mammal investigation in spotted fever focus with DNA-barcoding and taxonomic implications on rodents species from Hainan of China. PLoS ONE 7(8): e43479

[25] Luis, A.D., Hayman, D.T.S., O'Shea, T.J., Cryan, P.M., Gilbert, A.T., Pulliam, J.R.C., Mills, J.N., Timonin, M.E., Willis, C.K.R., Cunningham, A.A., Fooks, A.R., Rupprecht, C.E., Wood, J.L.N., and Webb, C.T. 2013. A comparison of bats and rodents as a reservoir of zoonotic viruses: are bats special? Proceedings of The Royal Society 280: 2012-2753

[26] Malakar, A.K., Lakra, W.S., Goswami, M., Singh, M., and Mishra, R.M. 2012. Molecular identification of three Ompok species using mitochondrial COI gene. Mitochondrial DNA 23(1): 20-24

[27] Meyer, T.J., McLain, A.T., Oldenburg, J.M., Faulk, C., Bourgeois, M.G., Conlin, E.M., Mootnick, A.R., de Jong, P.J., Roos, C., Carbone, L., and Batzer, M.A. 2012. An Alu-based phylogeny of gibbons (Hylobatidae). Molecular Biology and Evolution 29(11): 3441-3450

[28] Mootnick, A.R. 2006. Gibbon (Hylobatidae) species identification recommended for rescue or breeding centers. Primate Conservations 21: 103-108

[29] Nagata, S., Nagase, H., Kawane, K., Mukae, N., and Fukuyama, H. 2003. Degradation of chromosomal DNA during apoptosis. Cell Death and Differentiation 10: 108-116

[30] Ngo, K.A., and Kramer, L.D. 2003. Identification of mosquito blood meals using Polymerase Chain Reaction (PCR) with order-specific primers. Journal of Medical Entomology 40:215-222

[31] Panday, R., Jha, D.K., Thapa, N., Pokharel, B.R., and Aryal, N.K. 2014. Forensic wildlife parts and their products identification and individualization using DNA barcoding. The Open Forensic Science Journal 7: 6-13.

[32] Parson, W., Pegoraro, K., Niederstatter, H., Foger, M., and Steinlechner, M. 2000. Species identification by means of the cytochrome $b$ gene. International Journal of Legal Medicine 114: 23-28

[33] Pun, K.M., Albrecht, C., Castella, V., and Fumagalli, L. 2009. Species identification in mammals from mixed biological samples based on mitochondrial DNA control region length polymorphism. Electrophoresis 30(6): 1008-1014

[34] Ratnasingham, S., and Hebert, P.D.N. 2007. BOLD: The barcode of life data system (http://www.barcodinglife.org). Molecular Ecology Notes 7(3): 355-364

[35] Taberlet, P., Meye,r A., and Bouvet, J. 1992. Unusual mitochondrial DNA polymorphism in two local populations of blue tit Parus caeruleus. Molecular Ecology Resources 1(1): 27-36

[36] Tahseen, Q. 2014. Taxonomy-The crucial yet misunderstood and disregarded tool for studying biodiversity. Journal of Biodiversity and Endangered Species 2(3): 1-9

[37] Teletchea, F., Bernillon, J., Duffraisse, M., Laudet, V., and Hanni, C. 2008. Molecular identification of vertebrate species by oligonucleotide microarray in food and forensic samples. Journal of Applied Ecology 45: 967-975

[38] Tillmar, A.O., Dell'Amico, B., Welander, J., and Holmlund, G. 2013. A universal method for species identification of mammals utilizing next generation sequencing for the analysis of DNA mixtures. PLoS ONE 8(12): e833761 
[39] Tiwary, P., Kumar, D., Rai, M., and Sundar, S. 2012. PCR-RFLP based method for molecular identification of sand fly species Phlebotomus argentipes, Phlebotomus papatasi and Sergentomyia babu found in India. Journal of Medical Entomology 49(6): 1515-1518

[40] Vazirianzaeh, B., and Rahdar, M. 2013. Correct identification of animal host species is important in the diagnosis of zoonotic diseases. Jundishapur Journal of Microbiology 6(2): 97-99

[41] Wilson, D.E., and Reeder, D.M. 2005. Mammal species of the world: A Taxonomic and Geographic References (3 ${ }^{\text {rd }}$ ed.). Johns Hopkins University Press, Baltimore, 2142 pp

[42] Wodecka, B., Rymaszewska, A., and Skotarczak, B. 2014. Host and pathogen DNA identification in blood meals of nymphal Ixodes ricinus ticks taken from forest parks and rural forests of Poland. Experimental Applied of Acarology 62(4): 543-555 